\title{
ANSYS Workbench: Concrete Pavement Model
}

\author{
Shrikant M. Harle' ${ }^{1} \nless$ \\ Prakash S. Pajgade ${ }^{2}$ \\ 'B.E., MTech (Civil Engineering), Assistant Professor, Department of Civil Engineering, Professor Ram Meghe \\ College of Engg\& Management, Amravati, India \\ ¿B.E., MTech, PhD (Civil Engineering), Professor, Department of Civil Engineering, Professor Ram Meghe \\ Institute of Technology \& research, Amravati, India
}

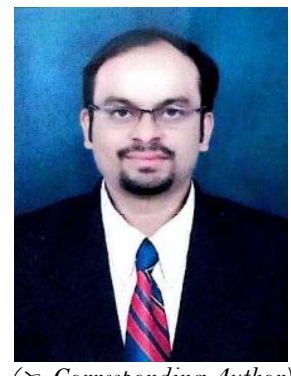

( Corresponding Author)

\begin{abstract}
Falling weight deflectometer (FWD) as well as the cores extracted from the concrete road slab were tested in the early days on plain cement concrete pavements which were laid in the Mumbai city. Before crushing the concrete cores the test of ultra sonic pulse velocity (UPV) was carried out. It was observed from the tests carried out that the deflections were within the limits set up by Indian codes as well as research carried out in other parts of world. Apart from it the concrete pavement model is also necessary to check the stresses and strain. The different components of stress and strain are observed through the graphics of software. The present paper consists of the stress, strain and deformation of the model after vehicular loads.
\end{abstract}

Keywords: ANSYS, Workbench, Concrete roads, Deformation, Principal stress, Strain.

Citation | Shrikant M. Harle; Prakash S. Pajgade (2017). ANSYS Workbench: Concrete Pavement Model. International Journal of Modern Research in Electrical and Electronic Engineering, 1(2): 5359.

\section{History:}

Received: 27 April 2017

Revised: 11 May 2017

Accepted: 24 May 2017

Published: 1 June 2017

Licensed: This work is licensed under a Creative Commons

Attribution 3.0 License $(\mathrm{cc}) \mathbf{E}$

Publisher:Asian Online Journal Publishing Group
Contribution/Acknowledgement: Both authors contributed to the conception and design of the study.

Funding: This study received no specific financial support.

Competing Interests: The authors declare that they have no conflict of interests.

Transparency: The authors confirm that the manuscript is an honest, Transparency: The authors confirm that the manuscript is an honest,
accurate, and transparent account of the study was reported; that no vital features of the study have been omitted; and that any discrepancies from the study as planned have been explained.

Ethical: This study follows all ethical practices during writing.

\section{Contents}

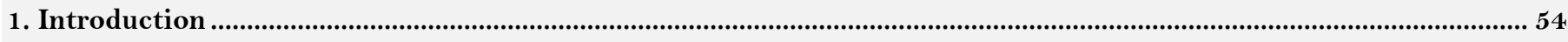

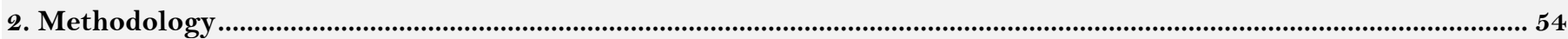

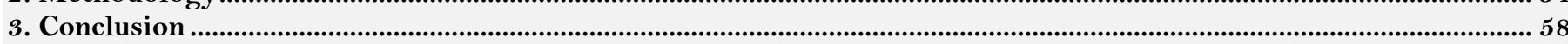

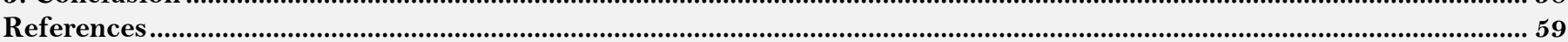




\section{Introduction}

Concrete pavements are the first choice in the areas which are prone to flood, even when the soil has low bearing capacity, when aggregates are of bad quality or of no standard sizes, or there is a issue of bad drainage in the area [1]. The Mumbai city of Maharashtra, India actually situated at sea level, the rainfall is also very heavy about $2000 \mathrm{~mm}$ during the monsoon seasons i.e. in the months of June to September, there is not proper provision to drain the water [2]. Cities like Mumbai which are the major commercial parts of India, need to cater the very heavy [3]. The single axle load in India is about 10.2 tonnes, but the common and improper practice to overload to 20 tonnes is generally found [4].Therefore the bituminous pavement deteriorates very easily as the potholes and cracks are formed on the roads. The reason behind replacing the bituminous roads with concrete roads are the common practice found in the majority part of Priya [5].

The mechanistic empirical models are generated to find the true behavior of the concrete road model through the numerical models which are subjected to vehicular loads are generated in the design [6]. The two dimensional finite element model which is axisymmetric is the mechanistic part generally developed through these software [7]. The mechanistic models are needed to know the dynamic stress and strain displacement response of the concrete pavement for any given traffic data consisting of traffic load and pavement layer properties [8].

\section{Methodology}

The concrete model using finite element software i.e. ANSYS is carried out. The figures and tables show the respective parameters of the concrete modeling using ANSYS. The analysis of model road patch is carried out, the results are also tabulated and figures are also used for describing it.

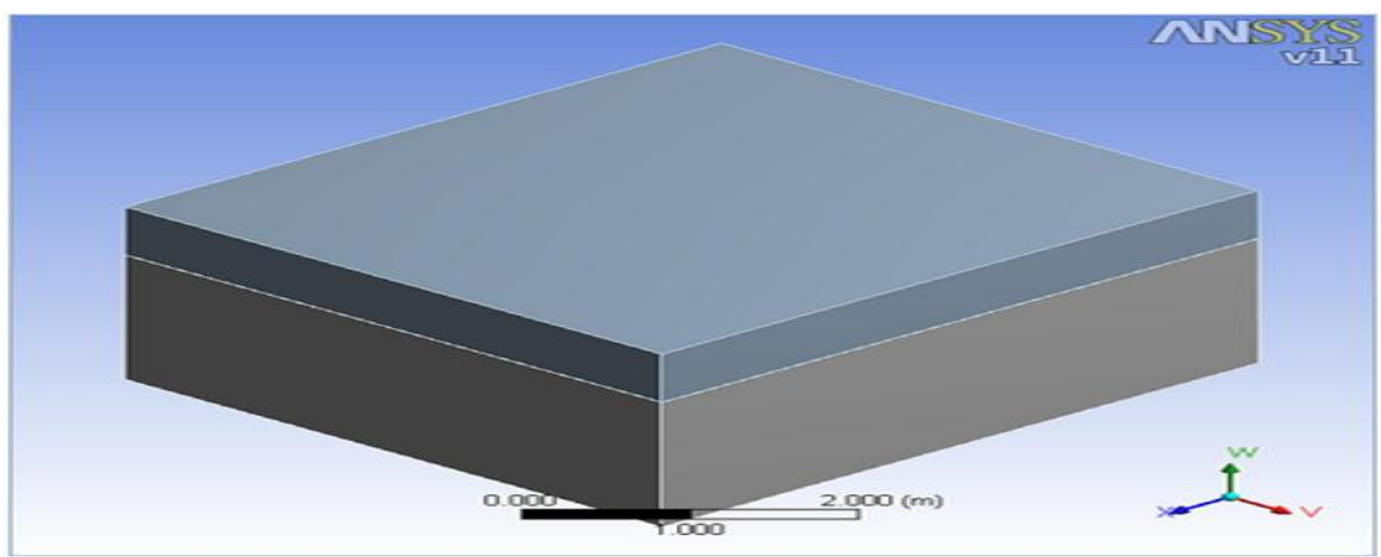

Figure-1. Model of Concrete road in ANSYS workbench

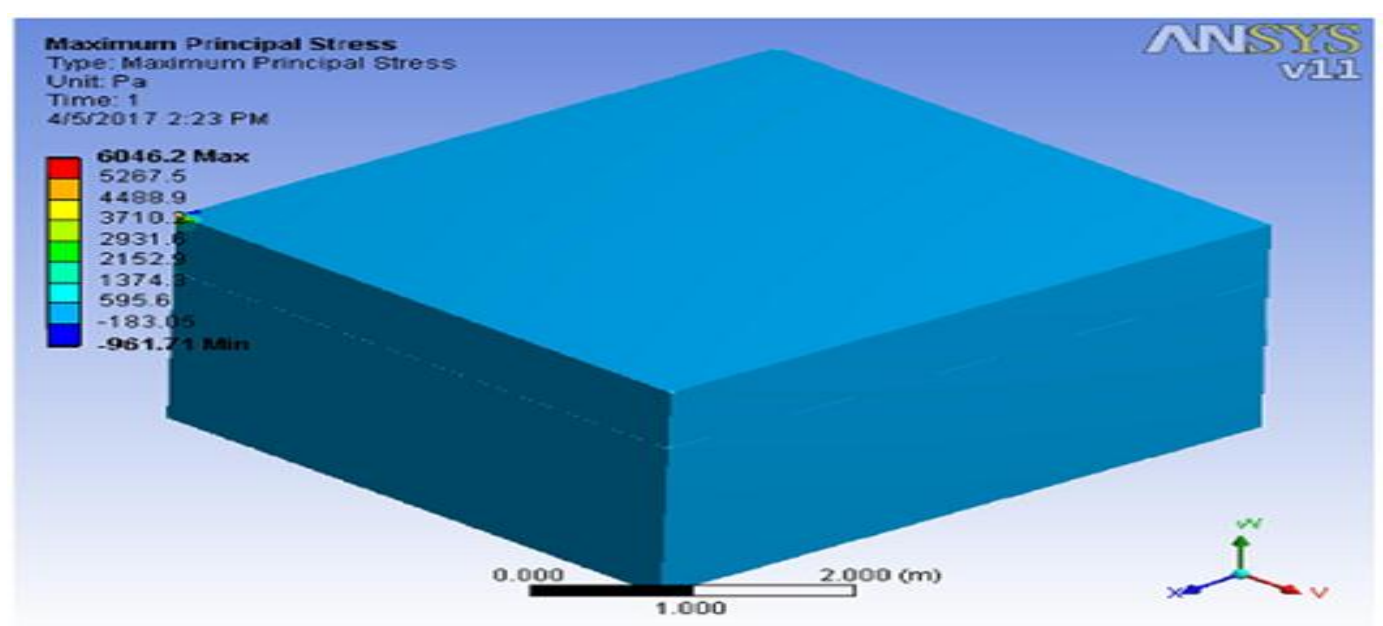

Figure-2. Maximum Principal stress

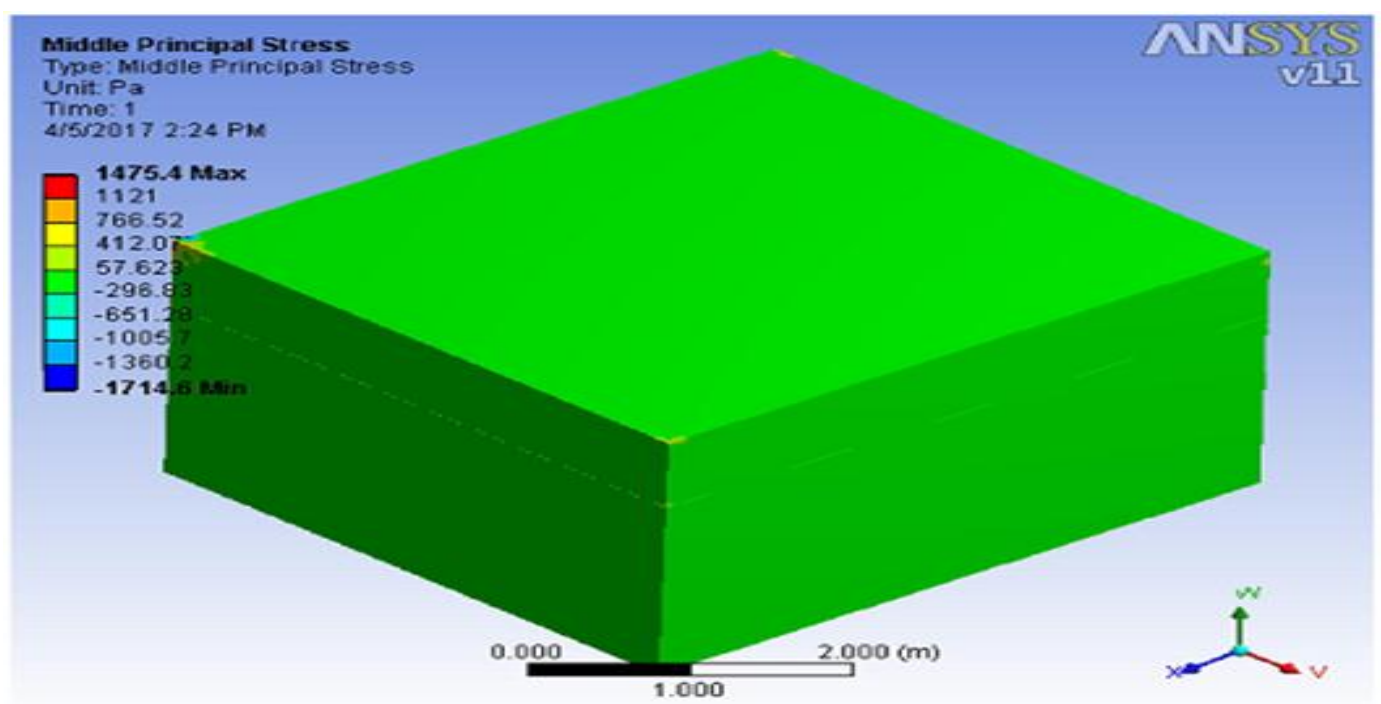

Figure-3. Middle Principal Stress 


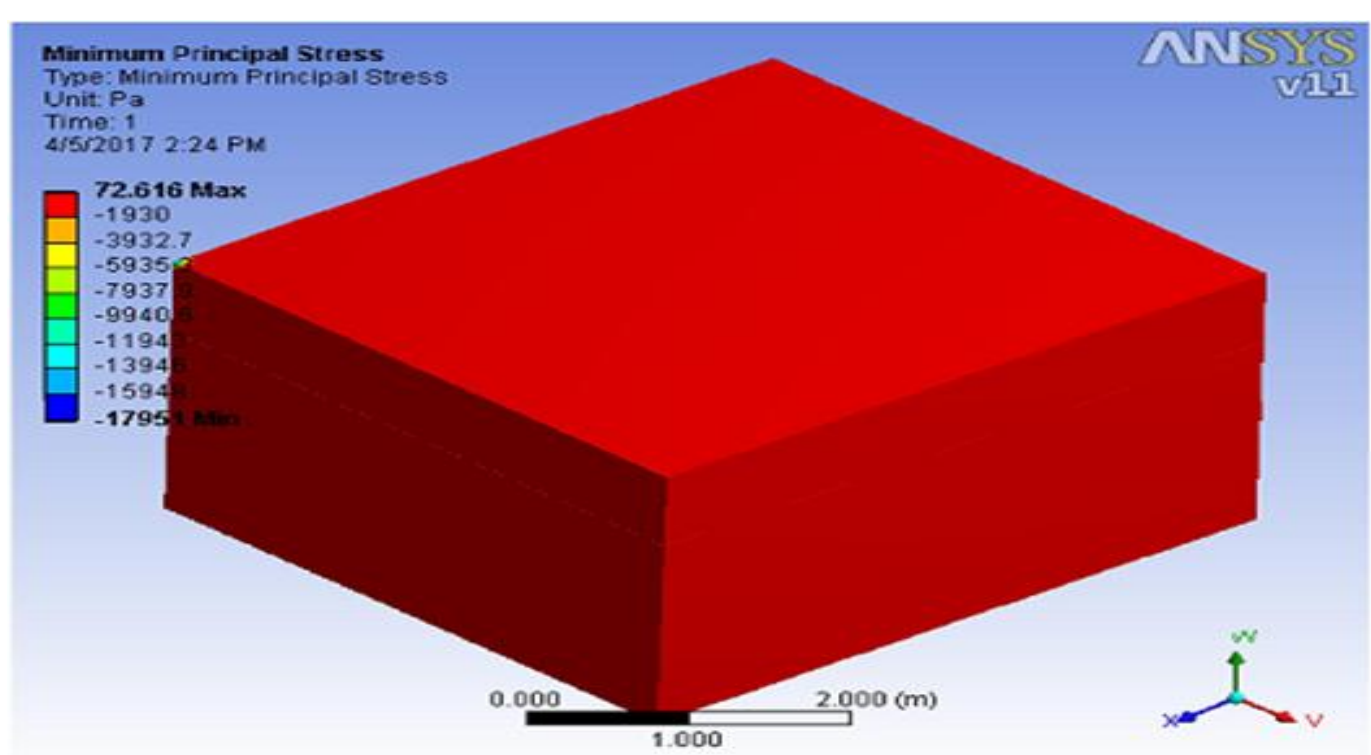

Figure-4. Minimum Principal Stress

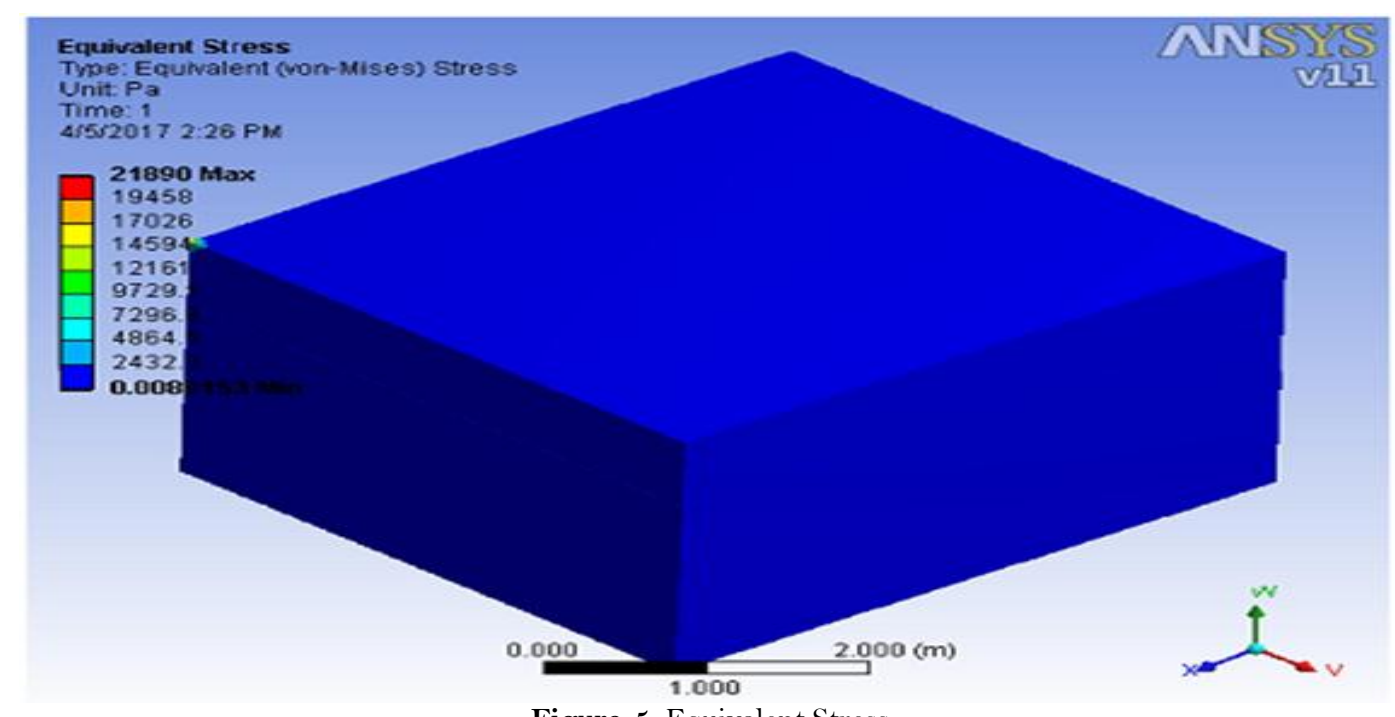

Figure-5. Equivalent Stress

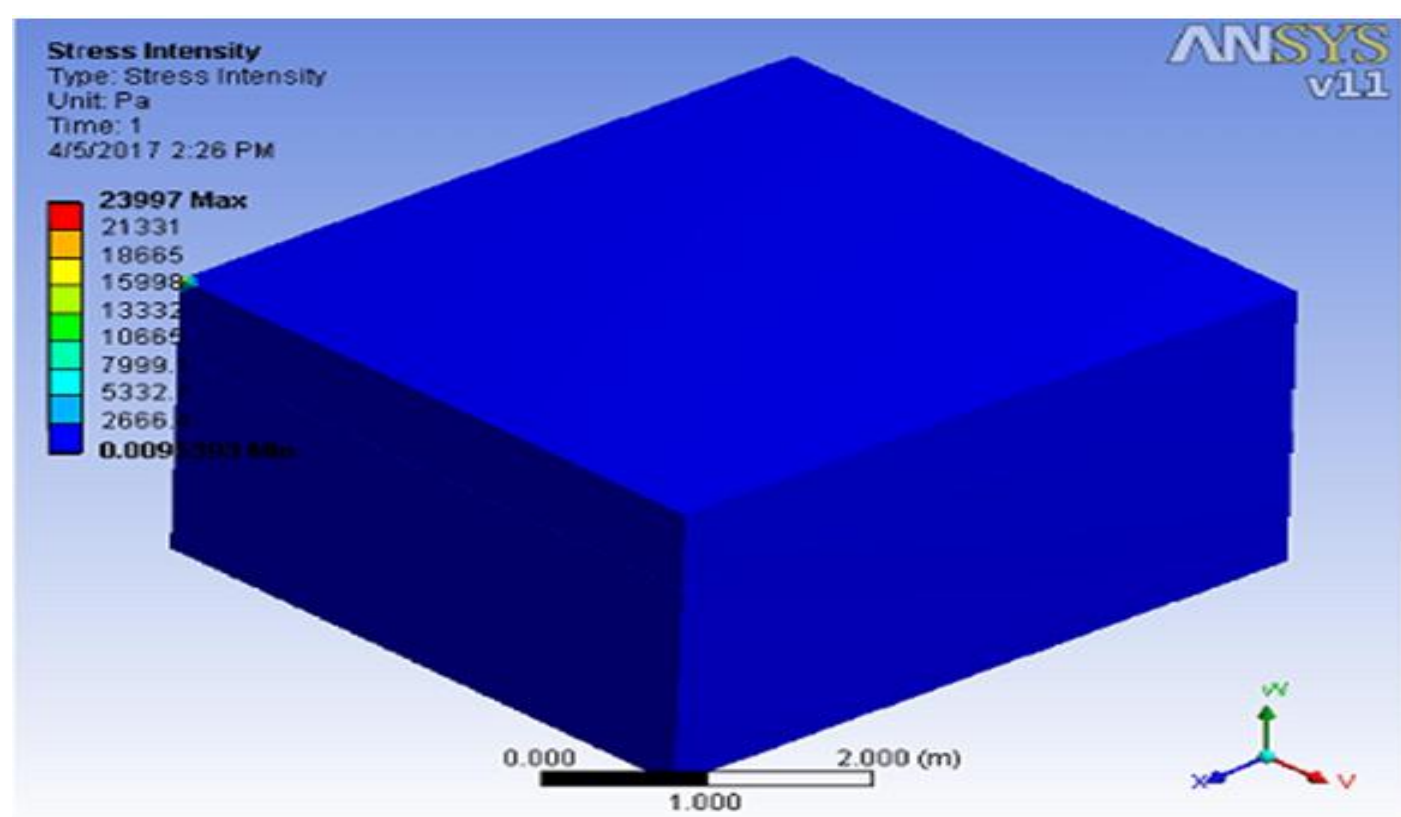

Figure-6. Stress Intensity of model 


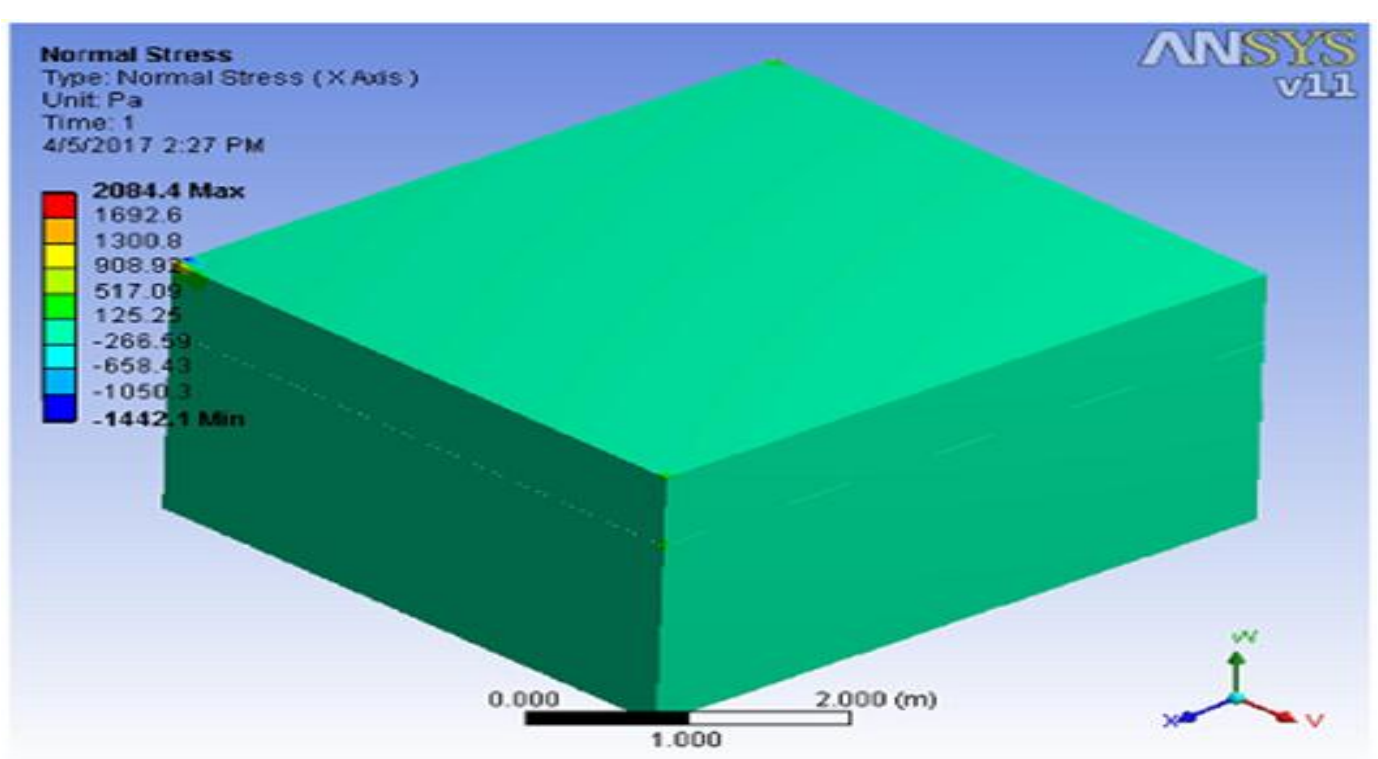

Figure-7. Normal Stress of model

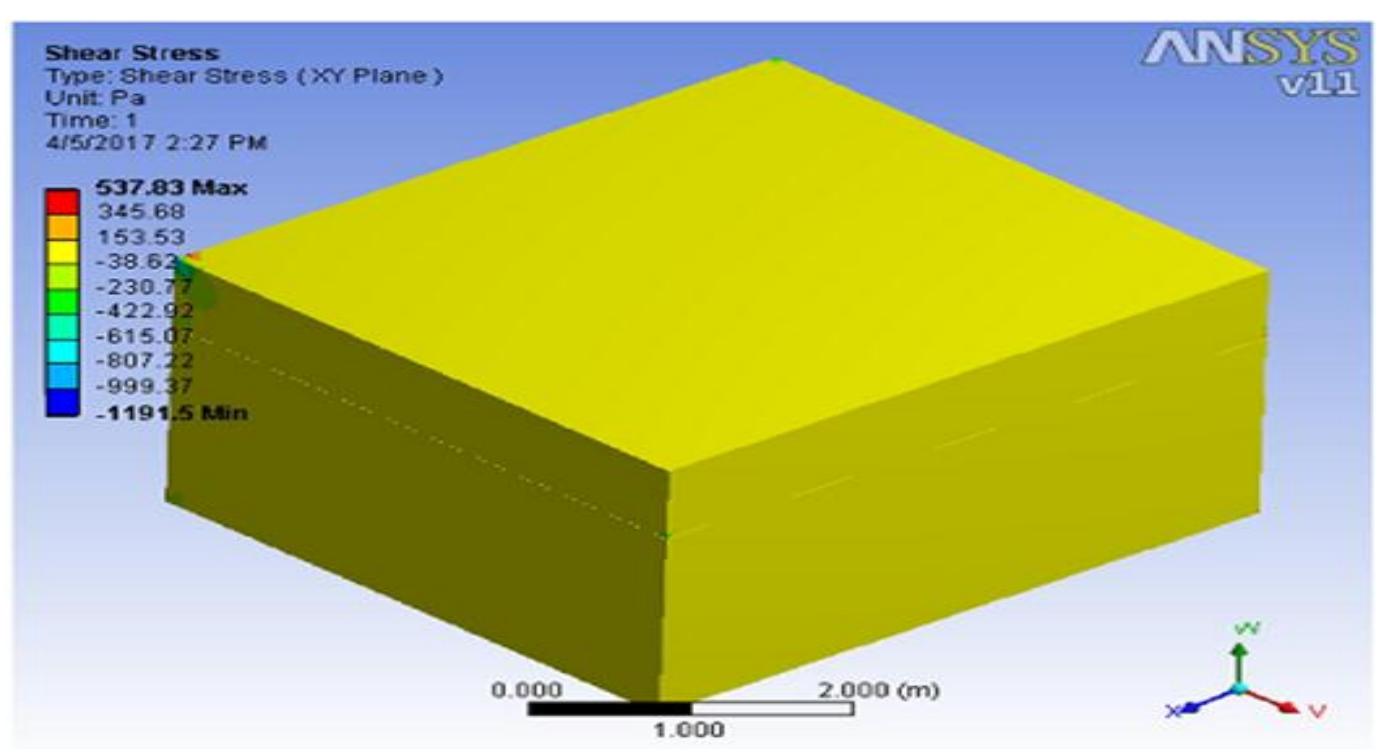

Figure-8. Shear Stress of model

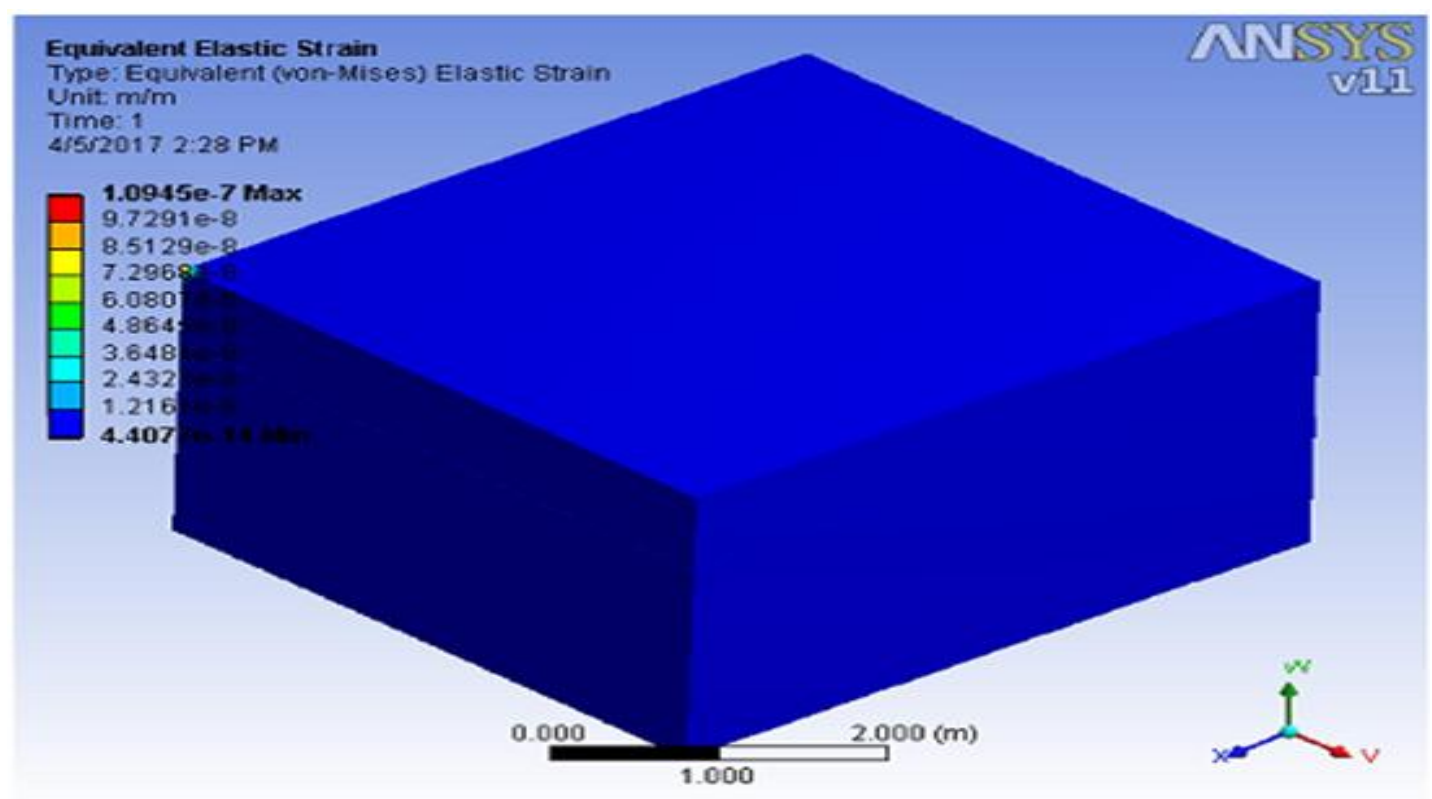

Figure-9. Equivalent Elastic strain 


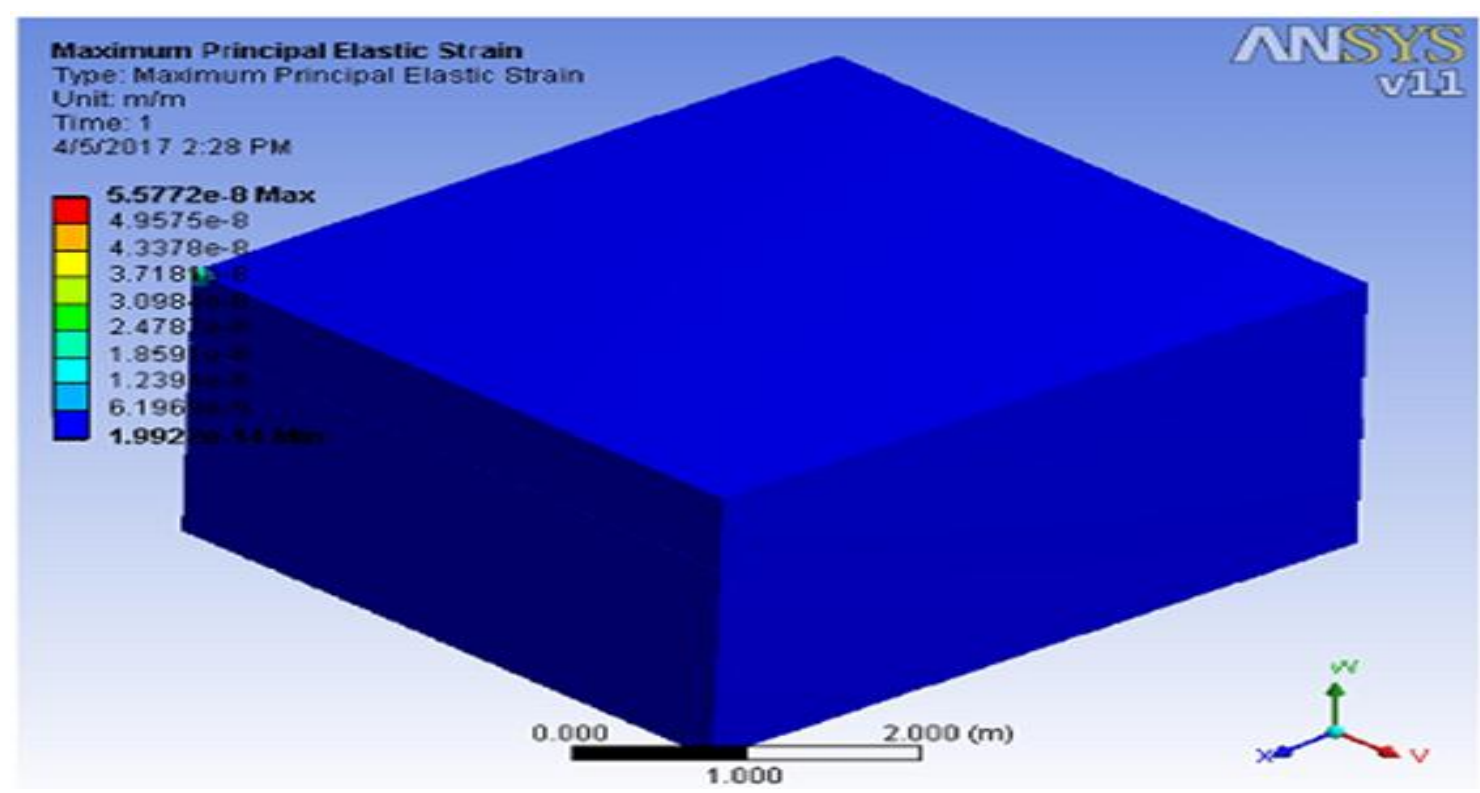

Figure-10. Maximum Principal Elastic Strain

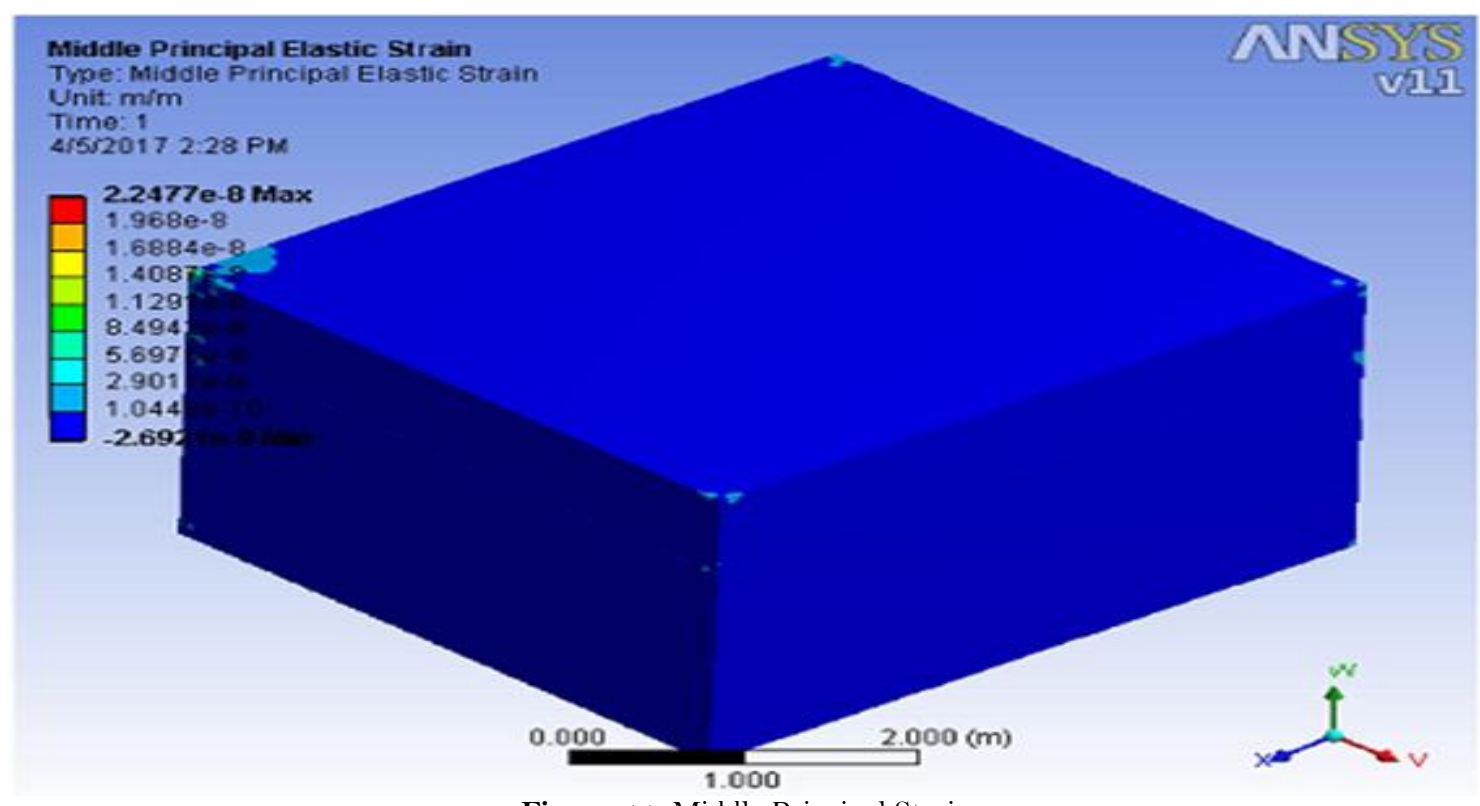

Figure-11. Middle Principal Strain

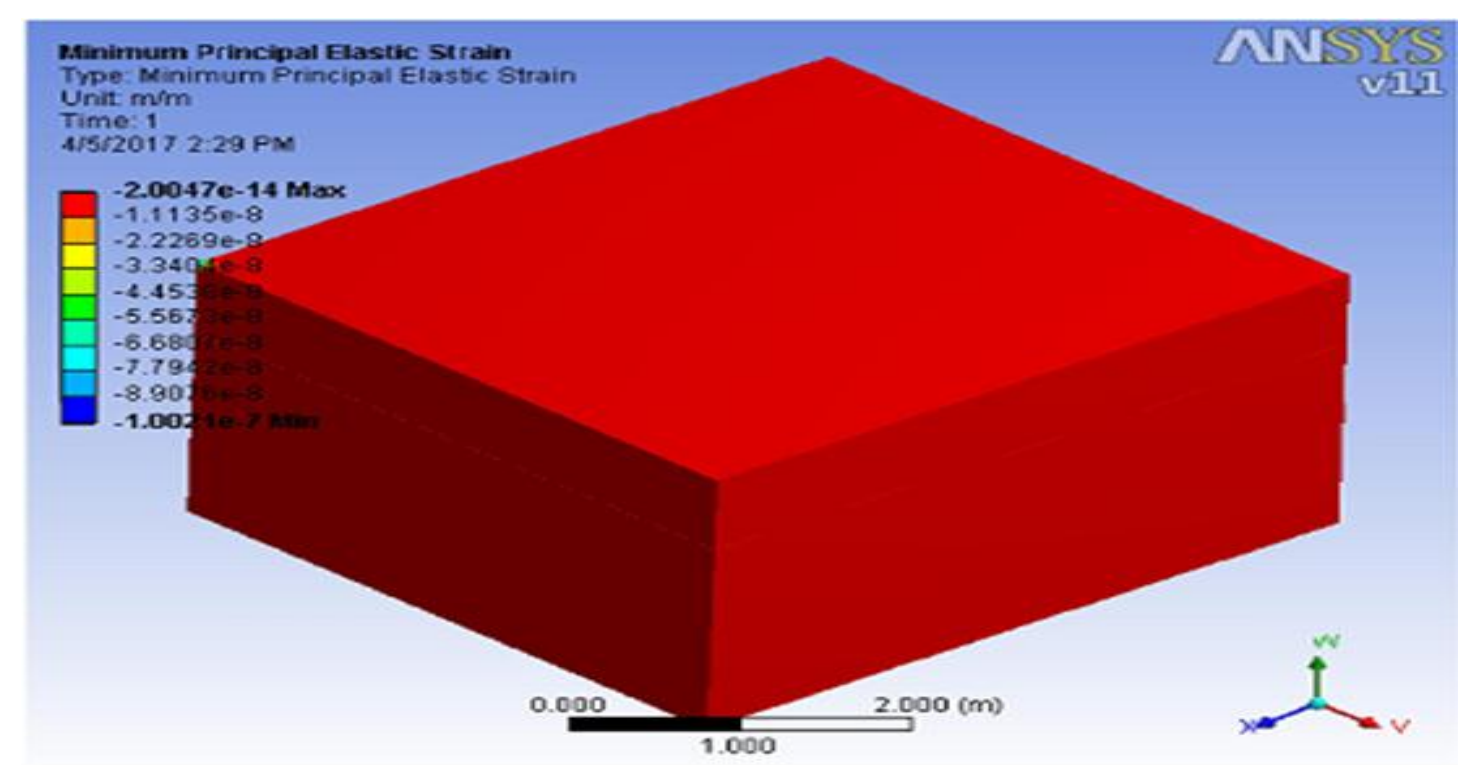

Figure-12. Minimum Principal Elastic Strain 


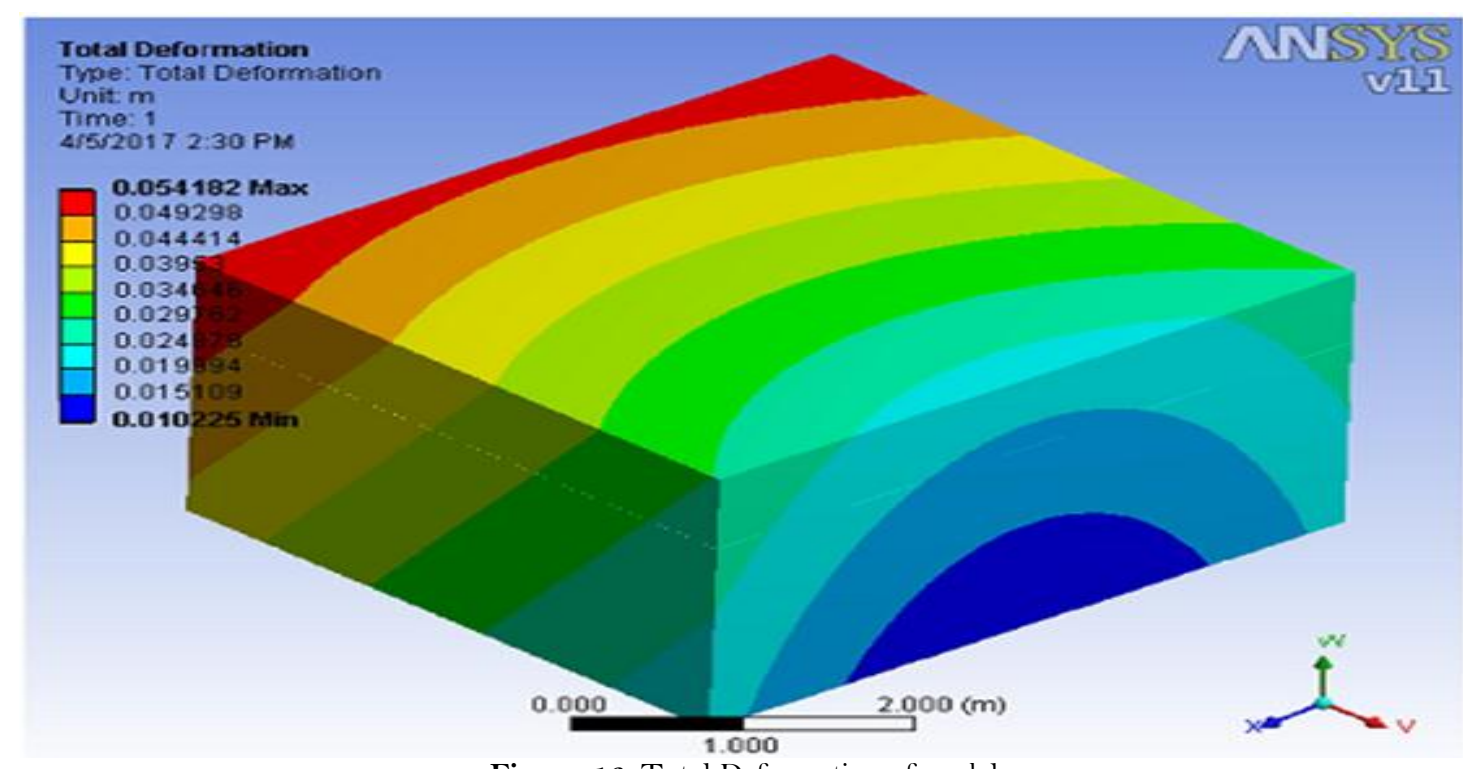

Figure-13. Total Deformation of model

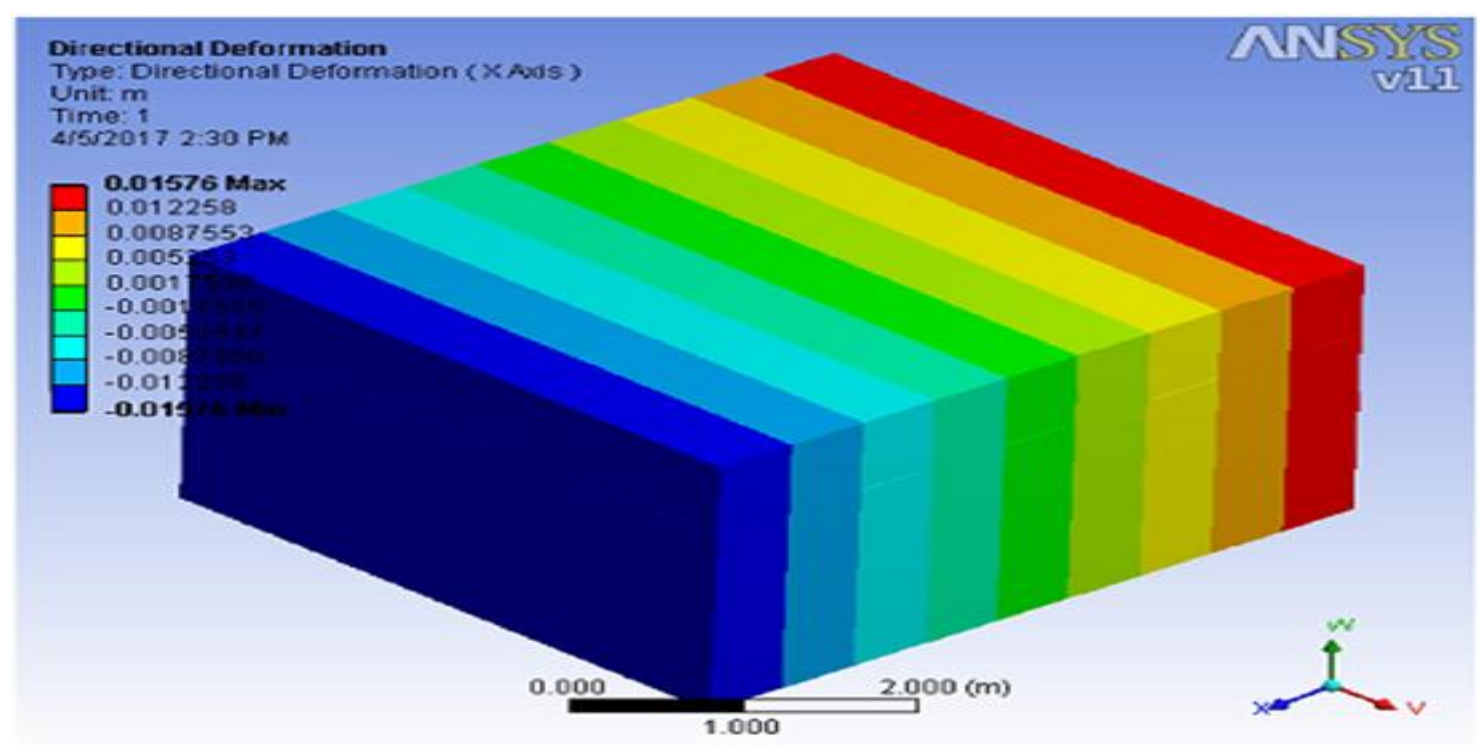

Figure-14. Directional Deformation

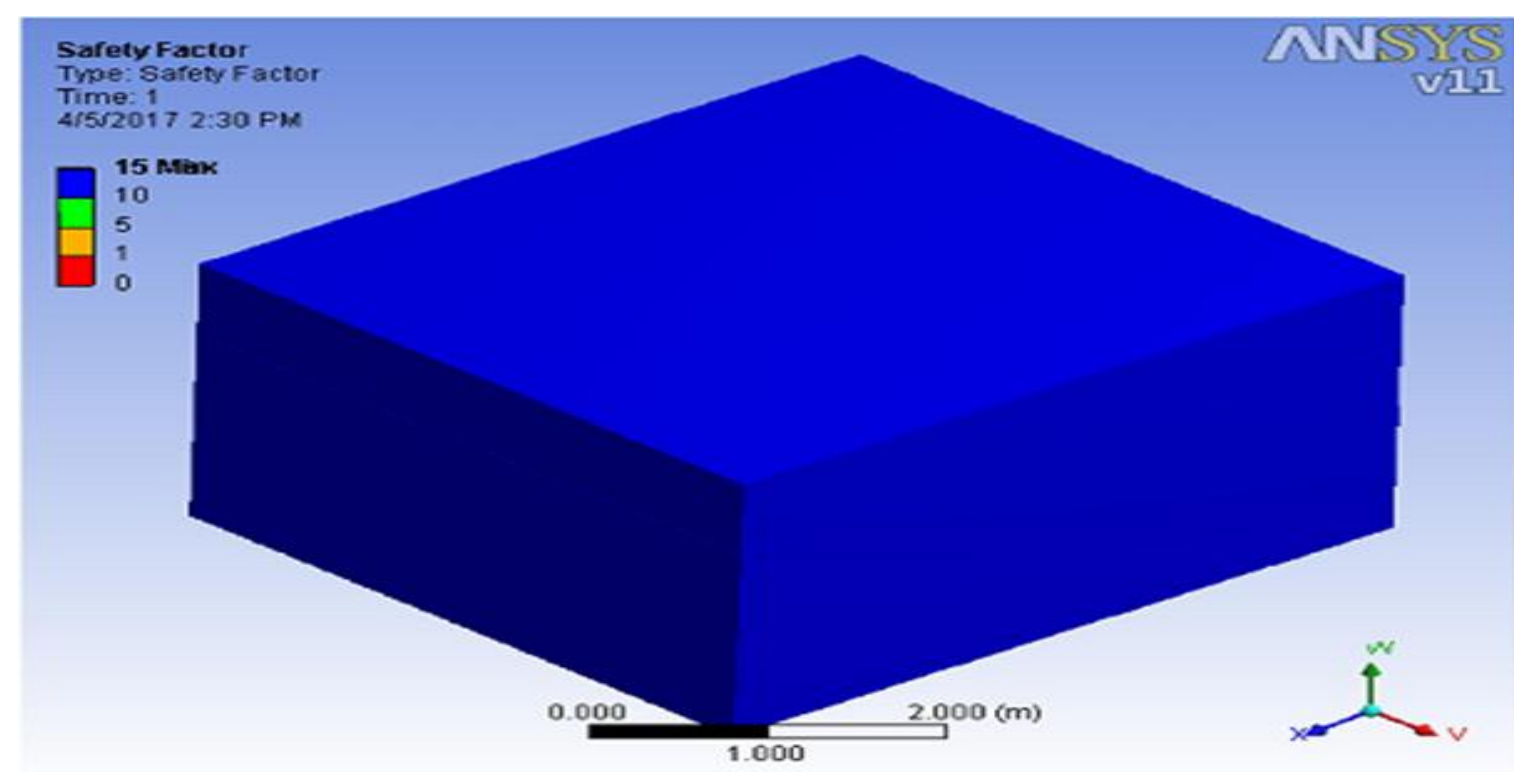

Figure-15. Safety Factor of model

\section{Conclusion}

From the above figures following conclusions are made:

- The maximum principal stresses on the model are uniformly distributed.

- The middle principal stresses are also uniformly distributed

- The minimum principal stresses are more on the surface of the model.

- Equivalent stress (von-mises) has very less intensity

- The normal stress is also distributed all across the model

- Shear stress is having negative intensity

- Middle, Maximum principal elastic strain and Equivalent elastic strain has less intensity

- The total deformation is maximum at the left edge of the model while it is minimum at right lower edge.

- The directional deformation is minimum at the left edge and maximum at the right edge.

- The safety factor is maximum. 


\section{References}

[1] D. Debajyoti, "Nonlinear finite element analysis of rectangular and skewed reinforced concrete Slab," ME Thesis, Department of Civil Engineering, Jadavpur University, Kolkata, 2010.

[2] P. Kitjapat and D. S. Elisa, "Nonlinear finite element for reinforced concrete slabs," Journal of Structural Engineering, ASCE, vol. 131, pp. $643-649$, 2005. View at Google Scholar

[3] G. Sheetal and S. V. Itti, "Study on two way RC slab using ANSYS with and without central opening," International Journal of Scientific Engineering and Technology, vol. 3, pp. 1108-1110 2014.

[4] M. Piyush and H. Shrikant, "Plastic cell filled concrete road: A review," Journal of Structural and Transportation Studies, vol. 1, pp. 115, 2016. View at Google Scholar

[5] B. Priya, "Finite element modeling of reinforced concrete slab," M.E. Thesis, Thapar University, Patiala, 2013.

[6] T. Subramani and S. Athulya, "Finite element analysis of thin walled-shell structures by ANSYS and LS-DYNA," International Journal of Modern Engineering Research, vol. 2, pp. 1576-1587, 2012. View at Google Scholar

[7] H. Shrikant and S. P. Prakash, "Cement grouted macadam: A review," Journal of Ceramics and Concrete Sciences, vol. 2, pp. 1-8, 2017. View at Google Scholar

[8] H. Shrikant and S. P. Prakash, "Analysis of plain concrete pavement in ANSYS," Journal of Construction E̊ Building Materials Engineering, vol. 3, pp. 1-10, 2017. View at Google Scholar 